\title{
ЭТНОПСИХОЛОГИЧЕСКИЕ ПЕРЕМЕННЫЕ КАК ПРЕДИКТОРЫ СОЦИАЛЬНО-ЭКОНОМИЧЕСКОГО РАЗВИТИЯ СТРАНЫ
}

\author{
А.А. ГРИГОРЬЕВ \\ ${ }^{a}$ ФГБУН Институт психологии РАН, 129366, Россия, Москва, ул. Ярославская, д. 13, к. 1
}

\section{Резюме}

В статье рассматриваются возможности предсказания социально-экономических показателей страны по национальному IQ и «личностным факторам», выделяемым в модели личности «Большая пятерка». Оценивается эффективность предсказания образовательных достижений, дохода на душу населения и уровня коррупции в стране. В качестве предикторов используются оценки национального IQ, представленные Р. Линном и Т. Ванханеном (Lynn, Vanhanen, 2012), и оценки по пяти личностным факторам, полученные в исследовании Д. Шмита с соавт. (Schmitt et al., 2007) для 56 стран и в исследовании Д. Бартрама (Bartram, 2013) для 29 стран. В исследовании Шмита с соавт. использовалась краткая методика оценки значений пяти личностных факторов (BFI), оценки Бартрама основывались на данных, полученных с помощью Профессионального личностного опросника (OPQ32). Результаты показывают следующее. 1. Оценки по пяти личностным факторам из исследования Шмита с соавт. сами не являются эффективными предикторами рассматриваемых социально-экономических показателей (значения нормированных квадратов коэффициентов корреляции ниже 0.1), и их присоединение к оценкам национального IQ ненамного повышает точность предсказания. 2. Оценки по пяти личностным факторам из исследования Бартрама являются удовлетворительными предикторами дохода на душу населения и уровня коррупции (нормированные квадраты коэффициентов корреляции равны 0.526 и 0.666); при объединении их с оценками национального IQ несколько увеличивается эффективность предсказания дохода на душу населения, но не уровня коррупции. 3. Национальный IQ является эффективным предиктором образовательных достижений страны (нормированный коэффициент корреляции равен 0.840 на выборке 49 стран и 0.845 на выборке 29 стран) и удовлетворительным предиктором дохода на душу населения (нормированный коэффициент корреляции равен 0.650 на выборке 52 стран и 0.411 на выборке 28 стран).

Ключевые слова: национальный IQ, личностные факторы, образовательные достижения, ВНД ППС, индекс восприятия коррупции.

Настоящая статья открывает серию публикаций, посвященных роли этнопсихологических переменных как факторов, определяющих роль страны в системе международных отношений, ее обороноспособность, 
возможности проведения самостоятельной политики, конкурентоспособность ее товаров, технологий и научных разработок, ее культурное влияние на другие страны. Под этнопсихологическими переменными имеются в виду стандартные психометрические показатели, выступающие как характеристики населения стран. Особое значение среди таких переменных придается рядом авторов психометрическому интеллекту (см.: Lynn, Vanhanen, 2006, 2012; Vanhanen, 2014). Рассматривались, однако, и «личностные факторы», главным образом в рамках модели личности «Большая пятерка» (Heine et al., 2008; Meisenberg, 2015; Mõttus et al., 2010). Однако вопрос о том, что может дать объединение данных об интеллекте с данными о личностных показателях для предсказания индексов развития страны или что может дать обращение к личностным показателям для объяснения больших отклонений действительных значений индексов развития страны от предсказанных по интеллекту, не рассматривался. В настоящей статье делается попытка оценить эффективность объединения данных о психометрическом интеллекте стран (национальном IQ) с национальными оценками показателей теста «Большая пятерка».

\section{Национальный IQ как предиктор достижений страны}

Связь интеллекта с большим числом показателей как на индивидуальном, так и на популяционном уровне была продемонстрирована в огромном количестве исследований. Здесь мы рассмотрим данные исследований на уровне стран.
Связь национального IQ с результатами международных исследований достижений в образовании (PISA, TIMSS, PIRLS и др.) была оценена Линном и Мейзенбергом (Lynn, Meisenberg, 2010), их оценка составила 0.907. Столь тесная связь позволяет использовать образовательные достижения стран в качестве альтернативной меры национального IQ или объединять их с измерениями IQ, образуя композитный показатель, что и было осуществлено (см.: Lynn, Vanhanen, 2012). Связь национального IQ с образовательными достижениями на уровне стран намного теснее, чем на индивидуальном уровне, где ее оценка составляет примерно 0.5 (см.: Kaufman et al., 2012).

Оценки национального IQ характеризуются связью с грамотностью взрослого населения страны, с долей лиц в возрасте 25 лет и старше, имеющих законченное среднее образование, и с долей лиц с высшим образованием. Соответствующие коэффициенты корреляции (взяты данные по показателям образования населения за 2008-2010 гг.) равны 0.691, 0.689 и 0.803 (Lynn, Vanhanen, 2012).

Национальный IQ связан с уровнем дохода населения страны: Линн и Ванханен привели коэффициент корреляции Пирсона своих оценок национального IQ с доходом на душу населения в стране, равный 0.592. Эта связь, однако, не вполне линейна. Использование нелинейной регрессии (как экспоненциальной, так и полиномиальной) для предсказания дохода на душу населения по национальному IQ вместо линейной приводит к увеличению доли объясняемой дисперсии дохода на душу 
населения (Lynn, Vanhanen, 2006). Как и в случае с образовательными достижениями, связь IQ с доходами на уровне стран, которую Линн и Ванханен (Lynn, Vanhanen, 2012) оценили на основании результатов ряда исследований величиной коэффициента корреляции примерно в 0.33, теснее, чем на уровне индивидов.

Национальный IQ связан с показателями здоровья населения страны: распространением недоедания во всем населении, недоеданием детей младше 5 лет, продолжительностью жизни, младенческой смертностью (до 1 года), долей ВИЧ-инфицированных среди лиц от 15 до 49 лет, частотой заболеваний туберкулезом. Соответствующие коэффициенты корреляции (взяты данные по показателям здоровья за 2000-2008 гг.) равны $-0.582,-0.468,0.759,-0.713$, -0.541 и -0.662 (Ibid).

Национальный IQ также связан с уровнем санитарии и преступности в стране и с рядом других переменных.

\section{Личностные черты как предиктор достижений страны}

Исследования связей личностных черт с показателями на уровне стран не столь многочисленны, как исследования аналогичных связей интеллекта, и охват их не столь широк, но они предоставляют достаточно материала для общей картины.

В одном исследовании (Heine et al., 2008) интересующие нас данные были получены в ходе проверки валидности как этнопсихологического показателя одного из факторов «Большой пятерки» - фактора Сознательность. Корреляция оценок стран по этому фактору, полученных в разных исследованиях, рассчитанная на различных выборках стран, с валовым внутренним продуктом на душу населения (ВВП) варьировала от 0.03 до -0.66 , а с продолжительностью жизни - от 0.33 до -0.51 . Частная же корреляция оценок по фактору «Сознательность» и продолжительности жизни при контроле ВВП (на различных выборках) варьировала от 0.39 до -0.42 .

В другом исследовании (Oishi, Roth, 2009; см.: Mõttus et al., 2010) сообщается о парадоксальном соотношении: в странах с более высокой психометрической сознательностью коррупция не ниже, а выше.

В еще одном исследовании (Mõttus et al., 2010) оценки по фактору Сознательность значимо коррелировали с частью критериальных показателей (максимальная корреляция была с ВВП), однако частные корреляции прочих показателей при контроле ВВП за редкими исключениями были незначимы.

Вероятно, наиболее масштабное исследование связей факторов теста «Большая пятерка» с рядом показателей провел Мейзенберг (Meisenberg, 2015). Он использовал оценки по факторам этого теста, полученные в пяти международных исследованиях, оценил согласованность полученных в этих пяти исследованиях оценок и рассмотрел связи всех пяти факторов с 12 критериальными показателями. Приведем полученные им результаты по некоторым показателям.

Показатель благосостояния (логарифм ВВП) обнаруживает значимые корреляции по данным большинства исследований со всеми факторами, 
кроме Нейротизма: по данным четыpex исследований - c фактором Экстраверсия; по данным трех - с факторами Открытость, Доброжелательность и Сознательность (с Нейротизмом - по данным двух исследований). Значимые корреляции с Доброжелательностью, однако, являются противоречивыми: одна из них отрицательная, две другие положительные. Остальные корреляции являются согласованными внутри факторов: с Сознательностью все они отрицательные, с остальными тремя - положительные. Из этих связей наиболее труднообъяснимой представляется связь с Экстраверсией. Показатель коррупции (индекс воспринимаемой коррупции) значимо (отрицательно) коррелирует по данным большинства исследований только с фактором Экстраверсия. С фактором Сознательность, связь с которым этого показателя предсказывалась, обнаружилась значимая корреляция (в ожидаемом направлении) в двух исследованиях. Показатель экономического роста обнаруживает единичные значимые корреляции; все-таки можно заключить, что по совокупности исследований он демонстрирует слабую отрицательную связь с Экстраверсией и Открытостью. В немногих случаях демонстрируют значимые корреляции логарифм частоты убийств и частота самоубийств.

Из приведенных результатов явствует, что эффективность предсказания таких показателей, как ВВП, индекс воспринимаемой коррупции и т.д., по национальным значениям факторов «Большой пятерки» не идет ни в какое сравнение с эффективностью предсказания этих переменных по национальному IQ. Если прибавить к этому довольно низкую согласованность оценок по факторам «Большой пятерки», полученных в разных исследованиях, то вопрос, сформулированный в названии статьи Г. Мейзенберга «Есть ли у нас валидные личностные показатели для уровня стран?», должен показаться вполне оправданным. Делались попытки объяснить эти, надо полагать малоприятные для исследователей, работающих в данной области, факты. Так, Ю. Аллик объясняет низкую согласованность оценок по факторам «Большой пятерки» в разных исследованиях низкой вариацией этих оценок между странами, что приводит к «зашумлению» их такими воздействиями, как неэквивалентность выборок, небольшие различия в переводах текстов методик и ошибки измерения (Allik, 2005). Г. Мейзенберг указывает на то, что не все версии теста «Большая пятерка» контролируют стиль ответов и эффект референтной группы (Meisenberg, 2015). Было показано, что стиль ответов варьирует от страны к стране (Meisenberg, Williams, 2008). Эффект референтной группы также составляет проблему в кросс-культурных исследованиях (см.: Heine et al., 2008).

По поводу этих объяснений можно сказать следующее. Ошибки измерения, источник несистематического смешения, приводящего к ненадежности оценок, могут контролироваться увеличением числа измерений. Представляется маловероятным, что в нескольких исследованиях отрицательные результаты вызваны отсутствием контроля 
надежности (тем более что в международных исследованиях выборки обычно достаточно большие). С другой стороны, если различия между странами по факторам «Большой пятерки» действительно небольшие, то едва ли эти факторы могут быть хорошими предикторами объективных критериев, и полученные в исследованиях отрицательные результаты не должны вызывать удивления. В таком случае продолжение исследований в данном направлении вряд ли можно считать целесообразным. Что же касается различной чувствительности разных версий теста к побочным переменным (т.е. их разной валидности), то это проблема решаемая, о бесперспективности дальнейших усилий в этом случае говорить не приходится.

Сделанные попытки проверки валидности факторов «Большой пятерки» на уровне стран ограничивались прослеживанием парных связей факторов с критериями. Это, по всей вероятности, связано с тем, что исследователи исходили из близости конструктов: они проверяли, будут ли коррелировать соотносимые по содержанию соответствующих конструктов переменные, - подход, обеспечивающий возможность последующего объяснения выявляемых связей. Представляется, однако, целесообразным, чтобы на первом этапе был оценен прогностический потенциал методики без принятия во внимание возможностей объяснения обнаруженных связей. Отрицательный результат такой оценки предотвратил бы бесполезную трату сил и средств и, возможно, направил бы исследователей на поиск в более перспективном направлении. В настоя- щем исследовании делается попытка такой оценки: используя множественную линейную регрессию, мы оценивали общий прогностический потенциал факторов Нейротизм (Эмоциональная стабильность), Экстраверсия, Открытость, Доброжелательность и Сознательность. Кроме того, оценивается, уточняют ли эти факторы предсказание, когда включаются в регрессионное уравнение, в котором исходным предиктором является интеллект (национальный IQ). Критериальными мерами являются образовательные достижения страны, валовый национальный доход на душу населения по паритету покупательной способности (ВНД ППС) и уровень коррупции в стране.

В данном исследовании особый интерес для нас представляет то, насколько точно можно предсказать значения данных критериальных мер для России.

\section{Переменные}

\section{Этнопсихологические переменные}

\section{Национальный IQ}

Оценки национального IQ взяты из книги Р. Линна и Т. Ванханена (Lynn, Vanhanen, 2012). Эти оценки базируются на данных нескольких сотен измерений интеллекта в разных странах в разное время. Они выражены в шкале IQ, основанной на британских стандартизациях использовавшихся тестов. Если в стране было проведено два измерения, в качестве оценки бралось их среднее, если больше двух измерений - медиана. Например, известны 
данные двух измерений IQ в Австрии в 1973 и 1981 гг. В одном результат был равен 98, в другом 101. В качестве оценки национального IQ в Австрии было взято среднее этих двух значений - 99.5. В Бразилии IQ измерялся семь раз в период с 1968 по 2007 г. Полученные значения варьировали от 84 до 92, с медианой 88. Это медианное значение было взято как оценка национального IQ в Бразилии.

Р. Линн и Т. Ванханен использовали не только оценки, полученные в результате прямых измерений интеллекта. Они, во-первых, добавили к ним оценки стран, в которых измерения не проводились, выведенные из измерений IQ в тех соседних странах, где население может считаться близким населению оцениваемой страны, и, во-вторых, агрегировали их с оценками образовательных достижений. Мы же - необходимо подчеркнуть - используем в настоящем исследовании в качестве оценок национального IQ только полученные в результате прямых измерений.

\section{Личностные факторы}

Используются оценки выраженности у населения стран пяти личностных факторов, полученные в двух исследованиях. В одном из этих исследований (Schmitt et al., 2007) была использована краткая методика оценки значений пяти личностных факторов (BFI: Big Five Inventory), состоящая из 44 пунктов. Респон- денты оценивали себя по 5-балльной шкале от 1 (совершенно не согласен) до 5 (полностью согласен). Данные были получены для 56 стран, оценки стран были выражены в Т-шкале. Во втором исследовании (Bartram, 2013) использовался Профессиональный личностный опросник OPQ32 (OPQ: Occupational Personality Questionnaires). Эта методика состоит из 104 четверок утверждений, утверждения в четверках входят в разные шкалы. В каждой четверке респондент выбирает одно наиболее соответствующее и одно наименее соответствующее ему утверждение. 416 утверждений образуют 32 шкалы опросника. Более трех четвертей этих шкал были объединены в пять факторов «Большой пятерки», при этом баллы по фактору «Нейротизм» были обращены и сам фактор назван «Эмоциональная стабильность». Приводятся оценки (в шкале стенов) для 29 стран $^{1}$.

\section{Критериальные меры}

\section{Образовательные достижения}

Использовались результаты международных исследований достижений в образовании по программам PISA (Program for International Student Assessment) и TIMSS (Trends in Mathematics and Science Study), данные пяти исследований по программе PISA (за 2000, 2003, 2006, 2009 и 2012 гг.) и четырех по программе TIMSS (за 1999, 2003,

\footnotetext{
${ }^{1}$ Хотя автор упоминает данные по 31 стране, приводятся данные по 29 существующим в настоящее время странам. Данные по Бельгии сообщаются для двух основных этнических групп, фламандцев и валлонов, раздельно. Мы усреднили их, получив оценки для страны в целом.
} 
2007 и 2011 гг.). Оценки образовательных достижений стран выводились следующим образом. (1) Для каждого исследования по программам PISA и TIMSS усреднялись оценки в каждой стране по предметам. Каждая страна получала число оценок, равное числу исследований, в которых она участвовала. (2) Не во всех странах дети в одинаковой мере охвачены образованием. Между тем результативность детей, охваченных образованием, выше результативности их не обучающихся сверстников примерно на половину стандартного отклонения (Lynn, Vanhanen, 2012). Таким образом, необходимо ввести поправку на охваченность детей образованием. Для этого мы оценили охваченность образованием детей релевантной возрастной группы в странах, участвовавших в исследованиях по программам PISA и TIMSS. Большинство оценок было вычислено из приведенных в отчете о результатах исследования по программе PISA в 2009 г. данных о численности детей возраста 15 лет, обучающихся в VII или более старших классах, и об общей численности детей этого возраста - как отношение этих величин. Для ряда стран, участвовавших в исследованиях по программе TIMSS, но не участвовавших в исследованиях по программе PISA, оценки либо были взяты из отчета о результатах исследования по программе TIMSS в 2011 г. с прибавлением поправки, требующейся, как нам представляется, для совмещения двух источников, либо же им были присвоены оценки соседних стран. Приняв разницу между охваченными и не охваченными образованием детьми равной половине стандартно- го отклонения (для PISA это составило 47.5, а для TIMSS 42.5 единицы шкал, в которых представлены оценки), мы рассчитали взвешенные средние для популяций детей релевантной возрастной группы. (3) На множестве стран, участвовавших во всех исследованиях по программе PISA, была построена стандартизированная шкала, в которой были выражены оценки всех стран, участвовавших в исследованиях по этой программе; аналогичным образом были выражены оценки стран, участвовавших в исследованиях по программе TIMSS. (4) Были усреднены оценки по исследованиям для каждой из двух программ. (5) Оценки по PISA и TIMSS были выражены в той же метрике, что и оценки национальных IQ, путем приравнивания средних и стандартных отклонений образовательных достижений к среднему и стандартному отклонению национальных IQ (средние и стандартные отклонения вычислялись на множестве стран, для которых имелись как оценки по PISA и/или по TIMSS, так и оценки национальных IO), и объединены для получения итоговых оценок: если имелись результаты как по PISA, так и по TIMSS, то итоговой оценкой было их среднее, в противном случае итоговой оценкой был результат, полученный по одной из программ.

Использованная нами процедура оценки образовательных достижений стран сходна с применявшейся другими авторами (Lynn, Meisenberg, 2010; Lynn, Vanhanen, 2012), хотя есть и отличия. Корреляция наших оценок с оценками этих авторов равна 0.96. Столь высокая корреляция позволяет считать наши и их 
оценки единым массивом. Собственно, мы могли бы просто воспользоваться их оценками. То, что мы произвели собственные расчеты, было вызвано желанием привлечь данные двух последних исследований - PISA-2012 и TIMSS-2011. Необходимо, однако, сказать, что Линн и Мейзенберг и Линн и Ванханен использовали не только результаты исследований по программам PISA и TIMSS, но и данные ряда других исследований. Это позволило им получить оценки для ряда стран, не участвовавших в исследованиях по программам PISA и TIMSS. Учитывая большое сходство их и наших оценок стран, участвовавших в этих программах, мы сочли возможным использовать их оценки для не участвовавших в этих программах стран.

\section{Доход}

В качестве показателя дохода населения страны использовался ВНД ППС, сведения о котором пуб- ликуются Мировым банком (http:/ data.worldbank.org). Использовались данные за 2014 г.

\section{Уровень коррупции}

В качестве оценок уровня коррупции в стране использовались значения индекса восприятия коррупции (CPI: Corruption Perceptions Index) за 2014 г. Индекс выражен в 100балльной шкале, где 100 означает самый низкий уровень воспринимаемой коррупции, а 0 - самый высокий. Он публикуется организацией Transparency International (см.: Transparancy International, 2014).

\section{Результаты}

Значения этнопсихологических переменных и критериальных мер представлены в таблицах 1 и 2. В таблице 1 приведены оценки по факторам «Большой пятерки», полученные в исследовании Д. Шмита с coaвт. (Schmitt et al., 2007) и данные по другим показателям для 56 стран,

Таблица 1

Национальный IQ, оценки по факторам «Большой пятерки», полученные в исследовании Шмита с соавт., образовательные достижения, ВНД ППС и индекс восприятия коррупции в 56 странах, участвовавших в исследовании Шмита и др. (Schmitt с coaвт., 2007)

\begin{tabular}{|l|c|c|c|c|c|c|c|c|c|}
\hline \multicolumn{1}{|c|}{ Страна } & IQ & H & Э & О & Д & С & Од & ВНд ППС & ИВК \\
\hline Австралия & 98 & 50.82 & 48.98 & 50.07 & 47.51 & 45.87 & 101 & 42880 & 81 \\
\hline Австрия & 99.5 & 49.69 & 50.61 & 49.29 & 45.9 & 46.73 & 98.66 & 45040 & 69 \\
\hline Аргентина & 96 & 55.05 & 49.1 & 50.83 & 42.75 & 48.18 & 86.54 & & 34 \\
\hline Бангладеш & 81 & 51.2 & 44.98 & 53.35 & 50.49 & 46.71 & & 3330 & 27 \\
\hline Бельгия & 99 & 53.6 & 45.99 & 54.59 & 45.07 & 43.03 & 100.17 & 43030 & 75 \\
\hline Боливия & 87 & 50.29 & 49.34 & 50.71 & 49.62 & 45.08 & & 6290 & 34 \\
\hline Ботсвана & 71 & 48.61 & 49.56 & 48.19 & 52.11 & 50.27 & $79.89^{*}$ & 16030 & 64 \\
\hline
\end{tabular}


Таблища 1 (продолжение)

\begin{tabular}{|c|c|c|c|c|c|c|c|c|c|}
\hline Страна & IQ & $\mathbf{H}$ & Э & $\mathbf{O}$ & Д & $\mathrm{C}$ & од & ВНд ППС & ИВК \\
\hline Бразилия & 87 & 53.14 & 45.89 & 49.16 & 45.86 & 45.38 & 85.44 & 15590 & 42 \\
\hline Великобритания & 100 & 51.39 & 49.79 & 45.97 & 47.31 & 46.89 & 99.83 & 38370 & 76 \\
\hline Германия & 99 & 50.29 & 50.31 & 47.8 & 45.08 & 46.52 & 99.45 & 46840 & 78 \\
\hline Гонконг & 108 & 52.41 & 46.91 & 41.64 & 42.69 & 41.53 & 103.47 & 56570 & 75 \\
\hline Греция & 92 & 53.19 & 48.6 & 51.53 & 52.42 & 47.45 & 95.09 & 26130 & 40 \\
\hline $\begin{array}{l}\text { Демократическая } \\
\text { Республика } \\
\text { Конго }\end{array}$ & 68 & 44.58 & 51.19 & 46.23 & 54.82 & 55.71 & & 650 & 22 \\
\hline Зимбабве & 71.5 & 48.26 & 48.69 & 48.52 & 49.77 & 51.75 & $72.99^{*}$ & 1630 & 21 \\
\hline Израиль & 95 & 49.27 & 48.65 & 50.95 & 49.44 & 52.4 & 93.41 & 32550 & 61 \\
\hline Индия & 82 & 50 & 47.42 & 48.48 & 50.43 & 47.36 & $86.12^{*}$ & 5640 & 36 \\
\hline Индонезия & 87 & 49.73 & 51.25 & 48.01 & 46.38 & 47.19 & 84.55 & 10190 & 32 \\
\hline Иордания & 84 & 49.86 & 48.35 & 47.1 & 53.73 & 49.77 & 86.93 & 11910 & 45 \\
\hline Испания & 97 & 54.03 & 49 & 49.64 & 45.26 & 46.8 & 97.11 & 32860 & 59 \\
\hline Италия & 97 & 51.66 & 49.8 & 50 & 46.52 & 48.62 & 96.48 & 34710 & 43 \\
\hline Канада & 100 & 50.58 & 48.32 & 48.75 & 49.14 & 49.05 & 101.96 & 43400 & 81 \\
\hline Кипр & & 51.44 & 49.1 & 49.36 & 51.16 & 48.49 & $91.8^{*}$ & 29800 & 63 \\
\hline Латвия & & 51.11 & 49.39 & 49.91 & 43.79 & 44.21 & 96.95 & 23150 & 53 \\
\hline Ливан & 82 & 53.35 & 48.32 & 49.4 & 46.1 & 44.56 & $87.18^{*}$ & 17190 & 28 \\
\hline Литва & 92 & 51.87 & 49.71 & 49.04 & 42.61 & 44.56 & 95.95 & 25390 & 57 \\
\hline Малайзия & 88.5 & 48.14 & 50.03 & 47.61 & 48.55 & 47.08 & 88.06 & 24080 & 50 \\
\hline Мальта & 97 & 52.35 & 50.45 & 50.66 & 49.56 & 45.97 & 93.4 & 27020 & 56 \\
\hline Марокко & 84 & 50.87 & 48.81 & 49.1 & 48.95 & 45.22 & $80.1^{*}$ & 7100 & 37 \\
\hline Мексика & 88 & 48 & 50.24 & 52.26 & 49.51 & 45.72 & 87.19 & 16500 & 34 \\
\hline Нидерланды & 100 & 48.61 & 49.75 & 49.94 & 46.08 & 43.91 & 101.22 & 47660 & 83 \\
\hline Новая Зеландия & 99 & 49.59 & 50.61 & 49.49 & 46.83 & 44.18 & 101.19 & 33760 & 91 \\
\hline Перу & 85 & 53.39 & 48.35 & 51.29 & 43.64 & 47.36 & 81.55 & 11440 & 38 \\
\hline Польша & 95 & 51.8 & 49.12 & 49.06 & 46.74 & 46.15 & 98.77 & 24090 & 60 \\
\hline Португалия & 94.5 & 50.21 & 48.06 & 50.29 & 49.52 & 47.75 & 95.99 & 28010 & 62 \\
\hline Румыния & 91 & 48.03 & 50.33 & 53.13 & 45.31 & 48.1 & 90.33 & 19030 & 43 \\
\hline Сербия & 89 & 50.17 & 51.95 & 52.44 & 47.64 & 47.53 & 90.98 & 12150 & 42 \\
\hline Словакия & 98 & 51.57 & 49.05 & 52.53 & 47.38 & 42.44 & 96.93 & 25970 & 47 \\
\hline Словения & 96 & 45.28 & 50.54 & 50.5 & 50.18 & 49.24 & 98.86 & 28650 & 57 \\
\hline
\end{tabular}


Таблица 1 (окончание)

\begin{tabular}{|l|c|c|c|c|c|c|c|c|c|}
\hline \multicolumn{1}{|c|}{ Страна } & IQ & $\mathbf{H}$ & $\mathbf{\Xi}$ & $\mathbf{O}$ & Д & $\mathbf{C}$ & ОД & ВНД ППС & ИВК \\
\hline США & 98 & 50 & 50 & 50 & 50 & 50 & 97.97 & 55860 & 73 \\
\hline Тайвань & 105 & 53.13 & 47.75 & 45.7 & 44.74 & 42.52 & 102.08 & & 61 \\
\hline Танзания & 72.5 & 47.73 & 49.19 & 48.19 & 49.26 & 53.27 & $77.73^{*}$ & 2530 & 33 \\
\hline Турция & 88.5 & 49.88 & 51.59 & 52.7 & 47.89 & 48.71 & 90.74 & 19020 & 50 \\
\hline Украина & 95 & 48.02 & 46.45 & 42.06 & 39.05 & 43.89 & $93.67 *$ & 8560 & 25 \\
\hline Фиджи & 85 & 48.03 & 49.68 & 47.21 & 49.27 & 46 & & 8030 & \\
\hline Филиппины & 90 & 51.41 & 48.12 & 49.34 & 47.96 & 43.14 & $79.39 *$ & 8380 & 36 \\
\hline Финляндия & 97 & 47.84 & 49.84 & 50.33 & 49.46 & 51.6 & 103.66 & 40000 & 89 \\
\hline Франция & 98 & 52.29 & 45.44 & 48.09 & 46.64 & 49.26 & 98.95 & 39720 & 71 \\
\hline Хорватия & 99 & 46.16 & 51.7 & 48 & 45.2 & 46.02 & 96.19 & 20560 & 48 \\
\hline Чехия & 98 & 51.02 & 50.22 & 50.59 & 44.09 & 42.87 & 98.77 & 26970 & 48 \\
\hline Чили & 91 & 51.39 & 47.55 & 54.69 & 47.02 & 49.72 & 90.37 & 21580 & 71 \\
\hline Швейцария & 101 & 48.72 & 50.47 & 52.62 & 47.69 & 45.03 & 100.49 & 59600 & 85 \\
\hline Эстония & 99 & 46.99 & 50.41 & 53.17 & 49.58 & 45.84 & 101.03 & 25690 & 68 \\
\hline Эфиопия & 68.5 & 46.12 & 47.11 & 47.15 & 51.82 & 54.36 & & 1490 & 33 \\
\hline Южная Африка & 72 & 49.01 & 49.61 & 49.01 & 49.97 & 49.61 & $70.67 *$ & 12700 & 42 \\
\hline Южная Корея & 106 & 53.99 & 44.86 & 44.3 & 44.11 & 40.6 & 103.47 & 34620 & 55 \\
\hline Япония & 105 & 57.87 & 46.73 & 41.53 & 42.21 & 37.82 & 102.47 & 37920 & 74 \\
\hline
\end{tabular}

Примечание. Обозначения для таблиц 1-7: IQ - национальный IQ; H - нейротизм; Э - экстраверсия; О - открытость; Д - доброжелательность; С - сознательность; ОД - образовательные достижения; ИВК - индекс восприятия коррупции.

* - данные по: Lynn, Vanhaneh, 2012.

участвовавших в этом исследовании; в таблице 2 - оценки по факторам «Большой пятерки», полученные в исследовании Д. Бартрама (Bartram, 2013), и данные по другим показателям для 29 стран, участвовавших в этом исследовании. В таблицах 3 и 4 представлены интеркорреляции для данных из таблиц 1 и 2 соответственно.

Как можно видеть из таблиц 3 и 4, оценки по факторам «Большой пятерки», полученные в исследова- нии Бартрама, теснее или не столь парадоксально коррелируют с критериальными мерами по сравнению с оценками, полученными в исследовании Шмита с соавт. Однако в настоящем исследовании нас интересуют не парные корреляции отдельных факторов, а общий прогностический потенциал по пяти личностным факторам, а также то, будет ли предсказание по национальному IQ и пяти личностным факторам более эффективным, 
Таблица 2

Национальный IQ, оценки по факторам «Большой пятерки», полученные в исследовании Бартрама, образовательные достижения, ВНД ППС и индекс восприятия коррупции в 29 странах, участвовавших в исследовании Бартрама

\begin{tabular}{|c|c|c|c|c|c|c|c|c|c|}
\hline Страна & IQ & ЭC & Э & $\mathbf{O}$ & Д & $\mathrm{C}$ & од & ВНД ППС & ИВК \\
\hline Австралия & 98 & 5.58 & 5.39 & 5.4 & 5.68 & 5.68 & 101 & 42880 & 81 \\
\hline Аргентина & 96 & 5.47 & 5.98 & 5.21 & 4.81 & 5.51 & 86.54 & & 34 \\
\hline Бельгия & 99 & 5.19 & 5.72 & 5.53 & 5.98 & 5.53 & 100.17 & 43030 & 75 \\
\hline Бразилия & 87 & 4.91 & 5.63 & 5.12 & 5.58 & 4.75 & 85.44 & 15590 & 42 \\
\hline Великобритания & 100 & 5.38 & 5.52 & 5.66 & 5.79 & 5.61 & 99.83 & 38370 & 76 \\
\hline Венгрия & 96.5 & 5.73 & 5.21 & 4.97 & 5.52 & 5.43 & 97.88 & 23830 & 54 \\
\hline Германия & 99 & 6.08 & 5.96 & 6.08 & 5.87 & 5.32 & 99.45 & 46840 & 78 \\
\hline Гонконг & 108 & 5.13 & 5.43 & 5.58 & 5.67 & 5.36 & 103.47 & 56570 & 75 \\
\hline Греция & 92 & 4.32 & 5.76 & 5.54 & 4.97 & 5.87 & 95.09 & 26130 & 40 \\
\hline Дания & 98 & 6.38 & 6.37 & 5.6 & 5.76 & 5.51 & 98.74 & 46160 & 91 \\
\hline Индия & 82 & 5.41 & 5.18 & 5.16 & 4.19 & 5.52 & $86.12^{*}$ & 5640 & 36 \\
\hline Индонезия & 87 & 4.98 & 5.02 & 5.08 & 5.18 & 4.93 & 84.55 & 10190 & 32 \\
\hline Испания & 97 & 4.79 & 5.75 & 5.61 & 5.4 & 5.13 & 97.11 & 32860 & 59 \\
\hline Италия & 97 & 5.09 & 5.7 & 5.86 & 5 & 5.02 & 96.48 & 34710 & 43 \\
\hline Канада & 100 & 5.83 & 6.39 & 5.24 & 5.68 & 5.64 & 101.96 & 43400 & 81 \\
\hline Китай & 105.5 & 5.46 & 5.13 & 5.03 & 5.91 & 5.36 & 108 & 13130 & 40 \\
\hline Малайзия & 88.5 & 4.9 & 4.58 & 5.11 & 5.29 & 5.17 & 88.06 & 24080 & 50 \\
\hline Нидерланды & 100 & 6.01 & 5.84 & 6.08 & 5.73 & 4.49 & 101.22 & 47660 & 83 \\
\hline Новая Зеландия & 99 & 5.61 & 5.2 & 5.27 & 5.91 & 6.18 & 101.19 & 33760 & 91 \\
\hline Норвегия & 100 & 6.22 & 6.29 & 5.3 & 6.14 & 5.26 & 98.42 & 65970 & 86 \\
\hline Польша & 95 & 4.99 & 4.64 & 5.84 & 4.75 & 5.35 & 98.77 & 24090 & 60 \\
\hline Португалия & 94.5 & 4.77 & 5.88 & 5.79 & 5.81 & 5.12 & 95.99 & 28010 & 62 \\
\hline Россия & 96.5 & 4.76 & 5.27 & 6.19 & 5.1 & 5.02 & 95.65 & 24710 & 28 \\
\hline США & 98 & 5.7 & 5.84 & 5.29 & 5.34 & 5.72 & 97.97 & 55860 & 73 \\
\hline Финляндия & 97 & 6.22 & 5.94 & 5.01 & 6.08 & 5.44 & 103.66 & 40000 & 89 \\
\hline Франция & 98 & 4.85 & 5.47 & 5.67 & 5.62 & 5.55 & 98.95 & 39720 & 71 \\
\hline Швеция & 99 & 6.24 & 6.37 & 5.61 & 6.28 & 5.83 & 98.98 & 46710 & 89 \\
\hline Южная Африка & 72 & 5.28 & 4.93 & 5.45 & 5.06 & 5.6 & $70.67^{*}$ & 12700 & 42 \\
\hline Япония & 105 & 4.46 & 5.16 & 6.45 & 5.62 & 4.15 & 102.47 & 37920 & 74 \\
\hline
\end{tabular}

* - данные по: Lynn, Vanhaneh, 2012. 
Интеркорреляции для данных из таблицы 1

\begin{tabular}{|l|c|c|c|c|r|r|r|r|}
\hline & Н & \multicolumn{1}{|c|}{ Э } & \multicolumn{1}{c|}{ О } & \multicolumn{1}{c|}{ Д } & \multicolumn{1}{c|}{ С } & \multicolumn{1}{c|}{ ОД } & ВНД ППС & ИВК \\
\hline IQ & 0.419 & -0.058 & -0.074 & -0.576 & -0.630 & 0.918 & 0.810 & 0.666 \\
\hline H & & -0.489 & -0.089 & -0.485 & -0.571 & 0.163 & 0.285 & 0.135 \\
\hline Э & & & 0.270 & 0.201 & 0.250 & -0.058 & 0.026 & 0.058 \\
\hline О & & & & 0.256 & 0.202 & -0.106 & -0.014 & 0.015 \\
\hline Д & & & & & 0.649 & -0.314 & -0.311 & -0.146 \\
\hline С & & & & & & -0.423 & -0.312 & -0.220 \\
\hline ОД & & & & & & & 0.805 & 0.726 \\
\hline ВНД ППС & & & & & & & & 0.868 \\
\hline
\end{tabular}

Таблица 4

Интеркорреляции для данных из таблицы 2

\begin{tabular}{|l|c|c|c|c|c|c|c|c|}
\hline & Н & Э & О & Д & С & ОД & ВНД ППС & ИВк \\
\hline IQ & 0.201 & 0.351 & 0.295 & 0.567 & -0.070 & 0.922 & 0.658 & 0.536 \\
\hline H & & 0.545 & -0.253 & 0.468 & 0.312 & 0.253 & 0.484 & 0.600 \\
\hline Э & & & 0.060 & 0.466 & 0.159 & 0.307 & 0.646 & 0.488 \\
\hline О & & & & 0.025 & -0.449 & 0.235 & 0.276 & 0.159 \\
\hline Д & & & & & 0.054 & 0.580 & 0.606 & 0.740 \\
\hline С & & & & & & 0.038 & 0.108 & 0.214 \\
\hline ОД & & & & & & & 0.584 & 0.609 \\
\hline ВНД ППС & & & & & & & & 0.814 \\
\hline
\end{tabular}

чем предсказание по одному национальному IQ. Для определения прогностических возможностей оценок по факторам «Большой пятерки» мы использовали множественную линейную регрессию: три критериальные меры, образовательные достижения, ВНД ППС и индекс восприятия коррупции предсказывались, во-первых, по национальному IQ, во-вторых, по пяти личностным факторам и, в-третьих, по национальному IQ и пяти личностным факторам. Это было проделано как для оценок Шмита с соавт., так и для оценок Бартрама. Показатели эффективности предсказания (нормированные квадраты коэффициентов корреляции) при использовании оценок из исследований Шмита с соавт. и Бартрама представлены в таблицах 5 и 6.

Значения таблицы 5 показывают, что оценки по факторам «Большой пятерки» из работы Шмита с соавт. сами не являются эффективными 
Таблица 5

Нормированные квадраты коэффициентов корреляции для уравнений регрессии при предсказании образовательных достижений, ВНД ППС и индекса восприятия коррупции по национальному IQ и пяти личностным факторам по оценкам Шмита с соавт.

\begin{tabular}{|l|c|c|c|}
\hline \multirow{2}{*}{ Критериальные меры } & \multicolumn{3}{|c|}{ Предикторы } \\
\cline { 2 - 4 } & IQ & $\begin{array}{c}\text { Пять личностных } \\
\text { факторов }\end{array}$ & $\begin{array}{c}\text { IQ + пять личностных } \\
\text { факторов }\end{array}$ \\
\hline ОД $(\mathrm{n}=49)$ & 0.840 & 0.096 & 0.847 \\
\hline ВНД ППС (n= 52) & 0.650 & 0.081 & 0.690 \\
\hline ИВК $(\mathrm{n}=53)$ & 0.433 & -0.028 & 0.478 \\
\hline
\end{tabular}

Таблии а 6

Нормированные квадраты коэффициентов корреляции для уравнений регрессии при предсказании образовательных достижений, ВНД ППС и индекса восприятия коррупции по национальному IQ и пяти личностным факторам по оценкам Бартрама

\begin{tabular}{|l|c|c|c|}
\hline \multirow{2}{*}{ Критериальные меры } & \multicolumn{3}{|c|}{ Предикторы } \\
\cline { 2 - 4 } & IQ & $\begin{array}{c}\text { Пять личностных } \\
\text { факторов }\end{array}$ & $\begin{array}{c}\text { IQ + пять личностных } \\
\text { факторов }\end{array}$ \\
\hline ОД $(\mathrm{n}=29)$ & 0.845 & 0.269 & 0.836 \\
\hline ВНД ППС (n=28) & 0.411 & 0.526 & 0.606 \\
\hline ИВК $(\mathrm{n}=29)$ & 0.261 & 0.666 & 0.661 \\
\hline
\end{tabular}

предикторами критериальных мер и их присоединение к оценкам национального IQ ненамного повышает точность предсказания. Оценки же из работы Бартрама, как видно из значений в таблице 6 , являются удовлетворительными предикторами двух критериальных мер - ВНД ППС и индекса восприятия коррупции (и как предикторы образовательных достижений они имеют преимущество перед оценками Шмита и др.). Как предикторы ВНД ППС и индекса восприятия коррупции они превосходят национальный IQ, так что в этих случаях лучше говорить не о включении личностных факторов в регрессионное уравнение, в котором исходным предиктором является интеллект, как сформулировано выше, а как минимум об объединении этих показателей. Их объединение при предсказании индекса восприятия коррупции ничего не дает по сравнению с предсказанием только по личностным факторам, равно как и присоединение оценок личностных факторов к оценкам национального IQ при предсказании образовательных достижений, но объединение 
оценок при предсказании ВНД ППС несколько увеличивает долю объясняемой дисперсии по сравнению с предсказанием только по личностным факторам (нормированный квадрат коэффициента корреляции увеличивается с 0.526 до 0.606 ). Сами же по себе оценки национального IQ являются эффективным предиктором образовательных достижений и удовлетворительным предиктором ВНД ППС. Однако индекс восприятия коррупции они удовлетворительно предсказывают только на большей выборке стран, охваченных исследованием Шмита с соавт.

Различие эффективности предсказания по оценкам из двух исследований может быть объяснено не только разным качеством оценок, но и разным составом выборок стран: в исследовании Шмита с соавт. страны третьего мира были представлены в большей степени. Чтобы проверить эту возможность, мы отобрали страны, данные по которым использовались в обоих исследованиях (23 страны), и сравнили на их множестве эффективность предсказания критериальных мер в этих исследованиях.
Показатели точности предсказания (нормированные квадраты коэффициентов корреляции) приведены в таблице 7 .

Значения в таблице 7 свидетельствуют о разном качестве оценок из двух исследований: оценки, полученные в исследовании Бартрама, превосходят оценки Шмита с соавт. в отношении возможности предсказания использованных нами критериальных мер. Это может объясняться краткостью методики, использованной Шмитом с соавт., а также тем, что применявшаяся при сборе данных, на которых основывались оценки Бартрама, процедура принудительного выбора имеет преимущество в тестировании личности перед шкалированием, использовавшимся в исследовании Шмита с соавт. (см.: Meisenberg, 2015).

Проведенное сопоставление качества оценок личностных факторов в двух исследованиях дает основание не только не использовать оценки, полученные в исследовании Шмита c соавт., в дальнейшем, но и пересмотреть результаты и выводы работ, в которых они уже использовались.

Таблииа 7

Нормированные квадраты коэффициентов корреляции для уравнений регрессии при предсказании образовательных достижений, ВНД ППС и индекса восприятия коррупции по национальному IQ и оценкам по пяти личностным факторам из работ Шмита с соавт. и Бартрама на множестве 23 стран

\begin{tabular}{|c|c|c|}
\hline \multirow{2}{*}{$\begin{array}{c}\text { Критериальные } \\
\text { меры }\end{array}$} & \multicolumn{2}{|c|}{ Предикторы } \\
\hline & $\begin{array}{c}\text { Оценки из исследования Шмита } \\
\text { с соавт. }\end{array}$ & $\begin{array}{c}\text { Оценки из исследования } \\
\text { Бартрама }\end{array}$ \\
\hline ОД & -0.160 & 0.355 \\
\hline ВНД ППС & -0.132 & 0.510 \\
\hline ИВК & -0.047 & 0.776 \\
\hline
\end{tabular}


Так, в работе Р. Линна (Lynn, 2007) невысокие творческие достижения некоторых народов, характеризующихся очень высоким национальным IQ, объясняются низкими значениями у них фактора Открытость, причем бо́льшая часть оценок стран по этому фактору взята из данного исследования. В свете проведенного анализа очевидно, что это объяснение не может считаться должным образом подтвержденным. В другой работе, одним из авторов которой является автор настоящей статьи (Григорьев, Сухановский, 2015), не удалось получить свидетельства влияния фактора Открытость, оценки которого брались из исследования Шмита с соавт., на творческие достижения стран, кроме того, эти оценки не характеризовались пространственной связностью. На основании этого было выражено сомнение в объяснительной ценности конструкта «Открытость» в популяционных исследованиях. Сомнение следовало бы адресовать использованным оценкам, а не конструкту.

Рассмотрим теперь, насколько точным является предсказание образовательных достижений, ВНД ППС и индекса восприятия коррупции в России по оценкам национального $\mathrm{IQ}$ и оценкам пяти личностных факторов, полученным в исследовании Бартрама.

Стандартизированный остаток при предсказании образовательных достижений в России по национальному IQ равен -0.394 , при предсказании по национальному IQ и факто- рам «Большой пятерки» он еще меньше: -0.155 . Таким образом, предсказание образовательных достижений в России по имеющимся этнопсихологическим переменным довольно точное, указаний на необходимость поиска других предикторов нет.

Стандартизированный остаток при предсказании ВНД ППС в России по национальному IQ равен -0.905 , при объединении национального IQ с личностными факторами он почти не меняется $(-0.903)^{2}$. Таким образом, хотя отклонение от предсказанного значения не выходит за пределы стандартной ошибки, оно приближается к этим пределам и требует объяснения.

Стандартизированный остаток при предсказании индекса восприятия коррупции в России по национальному IQ равен -2.075 , при объединении национального IQ с личностными факторами он увеличивается до -2.505 . Это очень большое отклонение от предсказанного значения. Мы вынуждены заключить, что ни национальный IQ, ни пять личностных черт, по крайней мере, как они были измерены в исследовании Бартрама, не могут быть полезными для объяснения уровня коррупции в России (очень высокого). Встает, таким образом, задача поиска иных факторов, которые могли бы объяснить уровень коррупции, дохода населения и, возможно, значение других показателей в России. Это задача для дальнейших исследований.

\footnotetext{
${ }^{2}$ Однако при предсказании только по личностным факторам он несколько ниже $(-0.757)$.
} 


\section{Литература}

Григорьев, А. А., Сухановский, В. Ю. (2015). География научного творчества. В кн. А. Л. Журавлев, Д. В. Ушаков, М. А. Холодная (ред.), Современные исследования интеллекта и творчест$в а$ (с. 172-188). М.: Изд-во «Институт психологии РАН».

Allik, J. (2005). Personality dimensions across cultures. Journal of Personality Disorders, 19(3), 212-232.

Bartram, D. (2013). Scalar equivalence of OPQ32: Big five profiles for 31 countries. Journal of CrossCultural Psychology, 44(1), 61-83.

Heine, S. J., Buchtel, E. E., \& Norenzayan, A. (2008). What do cross-national comparisons of personality tell us? The case of Conscientiousness. Psychological Science, 19(4), 309-313.

Kaufman, S. B., Reynolds, M. R., Liu, L., Kaufman, A. S., \& McGrew, K. S. (2012). Are cognitive g and academic achievement $\mathrm{g}$ one and the same g? An exploration on the Woodcock-Johnson and Kaufman tests. Intelligence, 40(2), 123-138.

Lynn, R. (2007). Race differences in intelligence, creativity and creative achievements. Mankind Quarterly, 48(2), 157-168.

Lynn, R., \& Meisenberg, G. (2010). National IQs validated for 108 nations. Intelligence, 38(4), 353-360.

Lynn, R., \& Vanhanen, T. (2006). IQ and global inequality. Augusta, GA: Washington Summit Publishers.

Lynn, R., \& Vanhanen, T. (2012). Intelligence: A unifying construct for the social sciences. London: Ulster Institute for Social Research.

Meisenberg, G. (2015). Do we have valid country-level measures of personality? Mankind Quarterly, 55(4), 360-382.

Meisenberg, G., \& Williams, A. (2008). Are acquiescent and extreme response styles related to low intelligence and education? Personality and Individual Differences, 44(7), 1539-1550.

Mõttus, R., Allik, J., \& Realo, A. (2010). An attempt to validate national mean scores of Conscientiousness: No necessarily paradoxical findings. Journal of Research in Personality, 44, 630-640.

Oishi, S., \& Roth, D.P. (2009). The role of self-reports in culture and personality research: it is too early to give up on self-reports. Journal of Research in Personality, 43, 107-109.

Schmitt, D. P., Allik, J., McCrae, R. R., \& Benet-Marthnez, V. (2007). The geographic distribution of big five personality traits: Patterns and profiles of human self-description across 56 nations. Journal of Cross-Cultural Psychology, 38(2), 173-212.

Transparency International. (2014). Retrieved from: http://www.transparency.org/cpi2014

Vanhanen, T. (2014). Global inequality as a consequence of human diversity. A new theory tested by empirical evidence. London: Ulster Institute for Social Research.

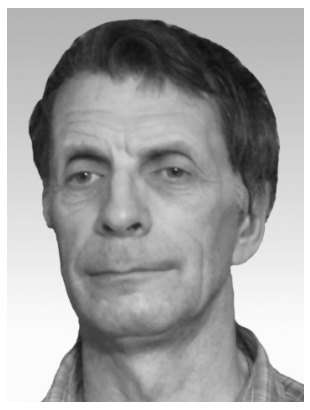

Григорьев Андрей Александрович - главный научный сотрудник, ФГБУН Институт психологии РАН, доктор филологических наук, доцент.

Сфера научных интересов: интеллект, индивидуальные различия, психолингвистика.

Контакты: andrey4002775@yandex.ru 


\title{
Ethnopsychological Variables as Predictors of Socio-Economic Development of a Country
}

\author{
A.A. Grigoriev ${ }^{\mathrm{a}}$ \\ ${ }^{a}$ Institute of Psychology of Russian Academy of Sciences, 13 build. 1, Yaroslavskaya str., Moscow, 129366, \\ Russian Federation
}

\begin{abstract}
The article observes the possibilities of predicting socio-economic characteristics of a country by national IQ and Big Five personality factors. The efficiency of predicting educational attainments, per capita income and corruption in a country are estimated. National IQs provided by Lynn and Vanhanen and estimates of five personality factors obtained in the study of Schmitt and al. for 56 countries and in the study of Bartram for 29 countries are used as predictors. In the study of Schmitt and al. the brief measure of five personality factors (BFI) was used; Bartram's estimates were based on the Occupational Personality Questionnaire (OPQ32). The results show the following. 1. The estimates of five personality factors obtained by Schmitt and al. are not effective predictors of the analyzed socio-economic characteristics (the values of adjusted $\mathrm{R}$ squared are lower 0.1) and their aggregating with national IQ not by much increases accuracy of prediction. 2. The estimates of five personality factors obtained by Bartram are satisfactory predictors of per capita income and corruption (the values of adjusted $\mathrm{R}$ squared equal 0.526 and 0.666); their aggregating with national IQ somewhat increases efficiency of prediction of per capita income but not corruption. 3. National IQ is an effective predictor of educational attainments of a country (the value of adjusted $R$ squared equals 0.840 for the sample of 49 countries and 0.845 for the sample of 29 countries) and satisfactory predictor of per capita income (the value of adjusted $R$ squared equals 0.650 for the sample of 52 countries and 0.411 for the sample of 28 countries).
\end{abstract}

Keywords: national IQ, personality factors, educational attainments, GNI PPP, corruption perceptions index.

\section{References}

Allik, J. (2005). Personality dimensions across cultures. Journal of Personality Disorders, 19(3), 212-232.

Bartram, D. (2013). Scalar equivalence of OPQ32: Big five profiles for 31 countries. Journal of CrossCultural Psychology, 44(1), 61-83.

Grigoriev, A. A., \& Sukhanovskii, V. Yu. (2015). Geografiya nauchnogo tvorchestva [The geography of scientific creativity]. In A. L. Zhuravlev, D. V. Ushakov, \& M. A. Kholodnaya (Eds.), Sovremennye issledovaniya intellekta $i$ tvorchestva [Contemporary studies of intelligence and creativity] (pp. 172-188). Moscow: Institute of Psychology of Russian Academy of Sciences.

Heine, S. J., Buchtel, E. E., \& Norenzayan, A. (2008). What do cross-national comparisons of personality tell us? The case of Conscientiousness. Psychological Science, 19(4), 309-313. 
Kaufman, S. B., Reynolds, M. R., Liu, L., Kaufman, A. S., \& McGrew, K. S. (2012). Are cognitive g and academic achievement $\mathrm{g}$ one and the same g? An exploration on the Woodcock-Johnson and Kaufman tests. Intelligence, 40(2), 123-138.

Lynn, R. (2007). Race differences in intelligence, creativity and creative achievements. Mankind Quarterly, 48(2), 157-168.

Lynn, R., \& Meisenberg, G. (2010). National IQs validated for 108 nations. Intelligence, 38(4), 353-360.

Lynn, R., \& Vanhanen, T. (2006). IQ and global inequality. Augusta, GA: Washington Summit Publishers.

Lynn, R., \& Vanhanen, T. (2012). Intelligence: A unifying construct for the social sciences. London: Ulster Institute for Social Research.

Meisenberg, G. (2015). Do we have valid country-level measures of personality? Mankind Quarterly, 55(4), 360-382.

Meisenberg, G., \& Williams, A. (2008). Are acquiescent and extreme response styles related to low intelligence and education? Personality and Individual Differences, 44(7), 1539-1550.

Mõttus, R., Allik, J., \& Realo, A. (2010). An attempt to validate national mean scores of Conscientiousness: No necessarily paradoxical findings. Journal of Research in Personality, 44, 630-640.

Oishi, S., \& Roth, D.P. (2009). The role of self-reports in culture and personality research: it is too early to give up on self-reports. Journal of Research in Personality, 43, 107-109.

Schmitt, D. P., Allik, J., McCrae, R. R., \& Benet-Marthnez, V. (2007). The geographic distribution of big five personality traits: Patterns and profiles of human self-description across 56 nations. Journal of Cross-Cultural Psychology, 38(2), 173-212.

Transparency International. (2014). Retrieved from: http://www.transparency.org/cpi2014

Vanhanen, T. (2014). Global inequality as a consequence of human diversity. A new theory tested by empirical evidence. London: Ulster Institute for Social Research.

Andrei A. Grigoriev - chief research fellow, Institute of Psychology of Russian Academy of Sciences, D.Sc., associate professor.

Research area: intelligence, individual differences, psycholinguistics.

E-mail: andrey4002775@yandex.ru 